\title{
THERMODYNAMIC PROPERTIES CALCULATION OF AIR - WATER VAPOR MIXTURES THERMAL PLASMAS
}

\author{
A. K. KAGONÉ, N. KOHIO, W. C. YAGUIBOU, Z. KOALAGA AND F. ZOUGMORÉ
}

(Received 7 March 2018; Revision Accepted 26 April 2018)

\begin{abstract}
Knowledge of air-water vapor mixtures thermal plasmas thermodynamic properties is important to estimate the performances of electrical arc cutting in this gas by a circuit breaker. In this paper, air-water vapor mixtures thermal plasmas thermodynamic properties are calculated in a temperature range from $5000 \mathrm{~K}$ to $30000 \mathrm{~K}$. The calculations are carried out by supposing local thermodynamic equilibrium at pressure of $1 ; 5$ and $10 \mathrm{~atm}$. The obtained results show the influence of the water vapor initial proportion but also that of the pressure on these plasmas thermodynamic properties.
\end{abstract}

KEYWORDS: Mixture; plasma composition; thermal plasma; thermodynamic properties; circuit breakers.

\section{INTRODUCTION}

The electrical current breaking in some circuit breakers is obtained by separating electrodes in the air or in the compressed air. This electrodes separation generates an electrical arc which interacts with surrounding gas and creates plasma of this gas. Circuit breakers were the subject of several theoretical and experimental studies (André, et al., 2004; André, 1996; André, 1997, PP. 475-493; Abbaoui, et al., 1992; Andanson, et al., 1979; André, 1997, PP. 1339-1359). Some studies on the electrical arc have shown the influence of the insulator vapors (Koalaga, 1991; Cheminat, et al., 1986; Cheminat, 1989; Abbaoui, et al., 1993), the metals (Andanson, et al., 1979; Ouajji, et al., 1986; Andanson, et al., 1984) and the hydrogen (Koalaga, et al., 1991; Cheminat, et al., 1986; Cheminat, 1989; Abbaoui, et al., 1993) on the engendered plasmas characteristics. The objective of this study is to determine the influence of water vapor on air plasma characteristics for electrical current breaking, specifically on its thermodynamic properties. Several studies on plasmas thermodynamic properties were made (Maouhoub, 1997; André, et al., 2002; Aubreton, et al., 2004; Bussière, et al., 2001; Ghorui, et al., 2008; Hannachi, 2007; André, 1995) but in our knowledge, there are not yet works on the air-water vapor mixture plasma thermodynamic properties.

A bibliographical research shows that only the transport properties of water and argon mixture plasma
(Petr, 2008; Hrabovsky, et al., 2006) and those of pure water plasma (Aubreton, et al., 2008; Hrabovsky, et al., 1993) were already studied. So we undertake in this study the calculation of air-water vapor mixtures thermal plasmas thermodynamic properties. The mixture can be naturally formed because of air humidity. But the water vapor partial pressure in the atmospheric air even in zones with great humidity led to a maximum percentage of water vapor around $7 \%$ at temperature of $40^{\circ} \mathrm{C}$. As this value is not sufficient to bring enough hydrogen in the mixture, air-water vapor mixtures with high water vapor percentages is used in this study: $80 \%$ air- $20 \%$ water vapor, $50 \%$ air- $50 \%$ water vapor and $20 \%$ air- 80 $\%$ water vapor. The increase of water vapor in the mixture could be done during the breaking of the electrical current by water injection in the circuit breaker. The proportions of air and water vapor of chosen mixtures are given in volume. These three (03) mixtures are chosen to be able to determine the water vapor influence on the plasmas thermodynamic properties. Air and pure water vapor plasmas thermodynamic properties are also calculated in order to make comparisons.

This theoretical study completes our last works (Kagoné, et al., 2012, PP. 211-221; Kagoné, et al., 2012, P.012004; Kagoné, 2012; Kohio, et al., 2014, PP. 711-715; Kohio, et al., 2014, PP. 240-246) on the same plasmas. The objective of this study is to show water vapor influence on air plasma thermodynamic properties. It concerns calculation of mass density,

A. K. Kagoné, LA.M.E, Laboratoire de Matériaux et Environnement, Département de Physique, U.F.R/S.E.A, Université Ouaga I Pr Joseph KI - ZERBO, 03 BP 7021 Ouagadougou 03, Burkina Faso.

N. Kohio, LA.M.E, Laboratoire de Matériaux et Environnement, Département de Physique, U.F.R/S.E.A, Université Ouaga I Pr Joseph KI - ZERBO, 03 BP 7021 Ouagadougou 03, Burkina Faso.

W. C. Yaguibou, LA.M.E, Laboratoire de Matériaux et Environnement, Département de Physique, U.F.R/S.E.A, Université Ouaga I Pr Joseph KI - ZERBO, 03 BP 7021 Ouagadougou 03, Burkina Faso.

Z. Koalaga, LA.M.E, Laboratoire de Matériaux et Environnement, Département de Physique, U.F.R/S.E.A, Université Ouaga I Pr Joseph KI - ZERBO, 03 BP 7021 Ouagadougou 03, Burkina Faso.

F. Zougmoré, LA.M.E, Laboratoire de Matériaux et Environnement, Département de Physique, U.F.R/S.E.A, Université Ouaga I Pr Joseph KI - ZERBO, 03 BP 7021 Ouagadougou 03, Burkina Faso. 
enthalpy, specific heat capacity and sound velocity in the plasma. These parameters are necessary to determine the plasma enthalpy density and enthalpy flux. The values obtained constitute, in addition, the data usable for modeling of the discharges of arcs in the airwater vapor mixture.

\section{CALCULATION METHOD}

The plasma composition calculation constitutes the first step in the determination of its thermodynamic properties and its others characteristics.

\subsection{PLASMA COMPOSITION}

In the local thermodynamic equilibrium (LTE) regime, the studied plasmas (Table 1.) compositions calculation is based on the mass action laws using the method of Newton - Raphson (Kagoné, et al., 2012, PP. 211-221) in a temperature range from $5000 \mathrm{~K}$ to $30000 \mathrm{~K}$ at pressure of $1 ; 5$ and $10 \mathrm{~atm}$. We suppose that the air is constituted by $80 \%$ of nitrogen and $20 \%$ of oxygen in volume. The three values of the pressure are also considered to estimate the impact of the pressure on the plasmas thermodynamic properties. Given the temperature range considered here, the various chemical species taken into account in the plasma composition are electrons, diatomic molecules, neutral atoms and their corresponding ions charged one or two times: $\mathrm{e}^{-}, \mathrm{H}, \mathrm{N}, \mathrm{O}, \mathrm{H}_{2}, \mathrm{~N}_{2}, \mathrm{O}_{2}, \mathrm{OH}, \mathrm{HN}, \mathrm{NO}, \mathrm{H}^{+}, \mathrm{O}^{+}, \mathrm{N}^{+}$,

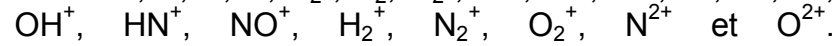

Table 1: Plasmas notation

\begin{tabular}{ll}
\hline Plasma name & Notation \\
\hline Dry air & Air \\
Mixture of $80 \%$ air and $20 \%$ water vapor & Mix 1 \\
Mixture of 50\% air and $50 \%$ water vapor & Mix 2 \\
Mixture of 20\% air and $80 \%$ water vapor & Mix 3 \\
Mixture of simple water vapor & Water \\
\hline
\end{tabular}

\subsection{MASS DENSITY}

The plasma mass density is determined from the following relation:

$\rho=\sum_{i=1}^{v} n_{i} m_{i}=\frac{M \cdot P}{R . T}$

where $n_{i}$ and $m_{i}$ are respectively numerical density and mass of particle $i . M$ is the plasma average molar mass, $R$ is the perfect gases constant and $P$ is the plasma pressure.

\subsection{ENTHALPY}

Knowing the various chemical species internal functions of partition, their numerical density and the plasma mass density, one can write (Koalaga, et al., 1993):

$$
H=\frac{1}{\rho} \sum_{i=1}^{v} H_{i} n_{i} m_{i}
$$

The enthalpy $H_{i}$ of each constitute is:

$H_{i}=\frac{1}{m_{i}}\left(\frac{5}{2} k T+k T^{2} \frac{\partial \ln Q_{\text {int }}(T)_{i}}{\partial T}+\Delta \varepsilon_{i}\right) \ldots \ldots .$.

$\Delta \varepsilon_{i}$ is the difference of energy between the fundamental level of each species $i$ and a common level of reference.

\subsection{SPECIFIC HEAT CAPACITY}

The plasma specific heat capacity at constant pressure $C_{P}$ is calculated by enthalpy numerical derivation:

$C_{P}=\frac{H(T+100)-H(T)}{100}$
Knowing the system specific internal energy $U$, its mass density and its specific enthalpy, one can determine its specific heat capacity at constant volume $C_{V}$, with the following expression (Koalaga, et al., 1993):

$C_{V}=C_{P}-R \frac{\left[Z_{f}+\left(\frac{\partial Z_{f}}{\partial \ln U}\right)_{P}\right]^{2}}{Z_{f}+\left(\frac{\partial Z_{f}}{\partial \ln U}\right)_{P}\left[1-\frac{U}{H}\left(\frac{\partial \ln U}{\partial \ln H}\right)_{T}\right]}$

$U=H-k T \sum_{i=1}^{v} \frac{n_{i}}{\rho}$

where $Z_{f}$ is the compressibility factor defined by:

$Z_{f}=\frac{P}{\rho R T}$

$R$ is the perfect gases constant and $P$ is the pressure.

\subsection{SOUND VELOCITY}

In a compressible fluid, the sound velocity $a$ can be written:

$$
a^{2}=\frac{P C_{P}}{\rho C_{V}} \frac{1+\left(\frac{T}{Z}\right)\left(\frac{\partial Z}{\partial T}\right)_{\rho}}{1+\left(\frac{T}{Z}\right)\left(\frac{\partial Z}{\partial T}\right)_{P}}
$$

where $Z$ is the compressibility of the medium. 
Hansen (Kagoné; 2012) shows that the equation (8) right-hand side second term of the member is generally near to 1 , so for a perfect gas:

$$
a^{2}=\frac{P C_{P}}{\rho C_{V}}
$$

\section{RESULTS}

We present the evolution, versus temperature, of the following thermodynamic properties: mass density $\rho$, enthalpy $H$, specific heat at constant pressure $C_{P}$ and sound velocity $a$ in plasma.

Other very significant parameters for the analysis of the arcs electrical extinction performances and their modeling are presented. Those are the enthalpy density (or enthalpy per unit of volume) $\rho H$ and the energy flux (or enthalpy flux) $\rho H a$. Some results of plasma composition calculation are presented briefly. Representatives figures of these different properties are figure 1 to figure 7 for a fixed pressure (1 atm) and figure 8 to figure 13 for a variable pressure (1, 5, $10 \mathrm{~atm})$. Calculations are applied to the plasmas indicated in table 1.

\subsection{WATER VAPOR INFLUENCE}

For a pressure $\mathrm{P}=1 \mathrm{~atm}$, Mix 2 plasma composition appears on figure 1 . These curves represent the evolution, versus temperature, of plasma particles numerical densities. We limited results to the Mix 2 case because the curves relate to the other mixtures (Air, Mix 1, Mix 3 and Water) present a great similarity of form with those of figure 1 . One could note on this figure that:

(i) The numerical density gradient of the diatomic neutral particles is very significant. The $\mathrm{N}_{2}$ numerical density is the most significant of all these diatomic particles at low temperature. This is to be attached to the high value of this particle dissociation energy;

(ii) The numerical density of the hydrogen atom $\mathrm{H}$ is higher than that of the other neutral atoms $(\mathrm{O}$, $\mathrm{N}$ ) in all the temperature range;

(iii) The electrons numerical density is primarily due to the ionization of the hydrogen atom when the temperature is higher than $15000 \mathrm{~K}$;

(iv) The numerical densities of the atoms doubly ionized are very low in all the range of temperature considered.

(v) In addition, it should be noted that the numerical density of the hydrogen atom in plasma increases with the percentage of water vapor in the mixture.

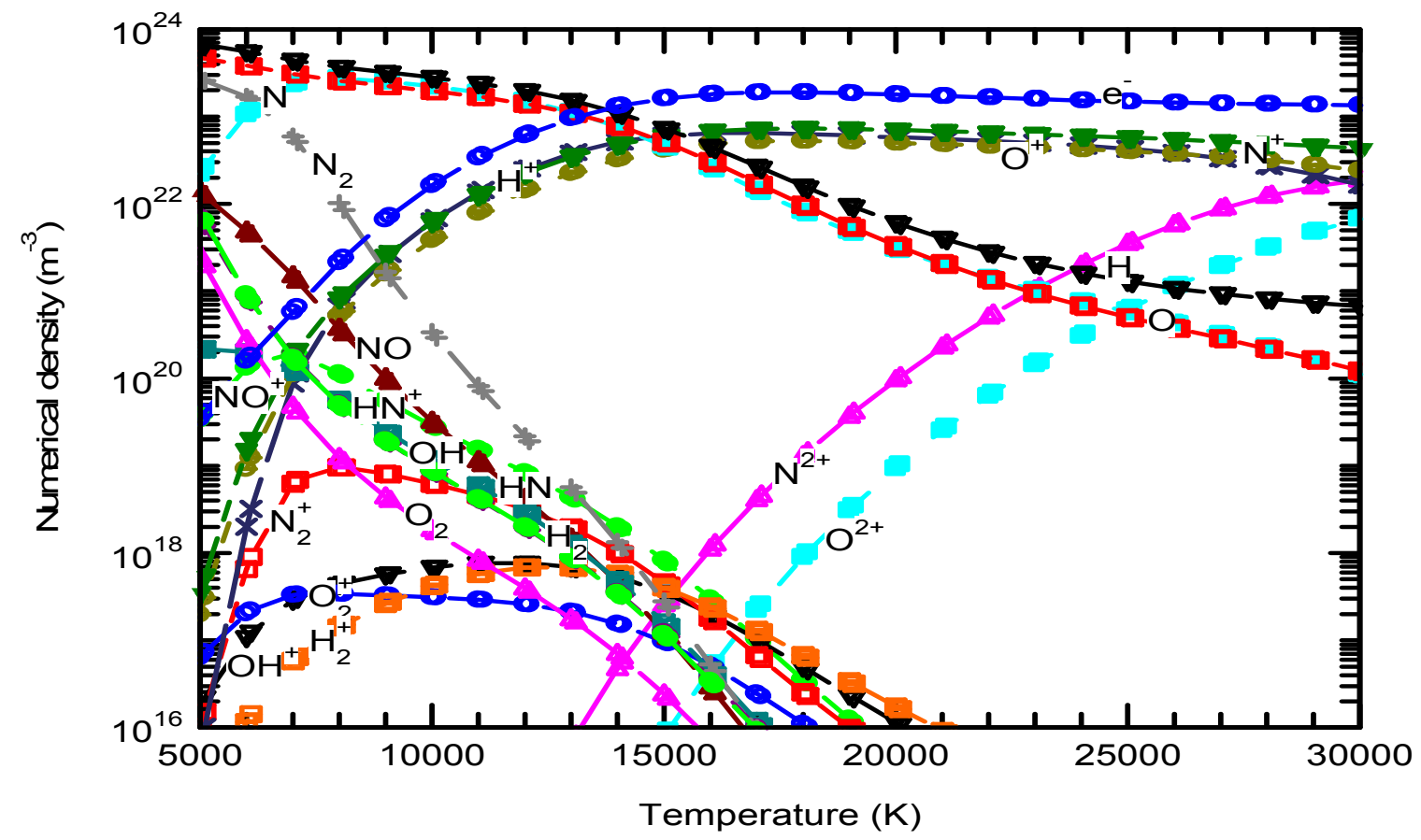

Fig. 1: Numerical density variation of Mix 2 plasma different particles versus temperature at pressure 1 atm.

\subsubsection{MASS DENSITY}

Figure 2 indicates the variation of the mass density $\rho$, versus temperature for the five studied plasmas. The evolution of $\rho(T)$ is identical for these plasmas. Thus, when the temperature increases, the mass density decrease. It should be noted that the aradient of $o(T)$ are much more sianificant at low temperature $(\mathrm{T}<9000 \mathrm{~K})$. This is a direct consequence of dissociations leading to the progressive disappearance of molecules as the temperature increases. In addition, at a same temperature, plasmas of the mixtures characterized by a strong percentage of water vapor (thus a strong percentage of hydrogen) have the lowest mass densities. 


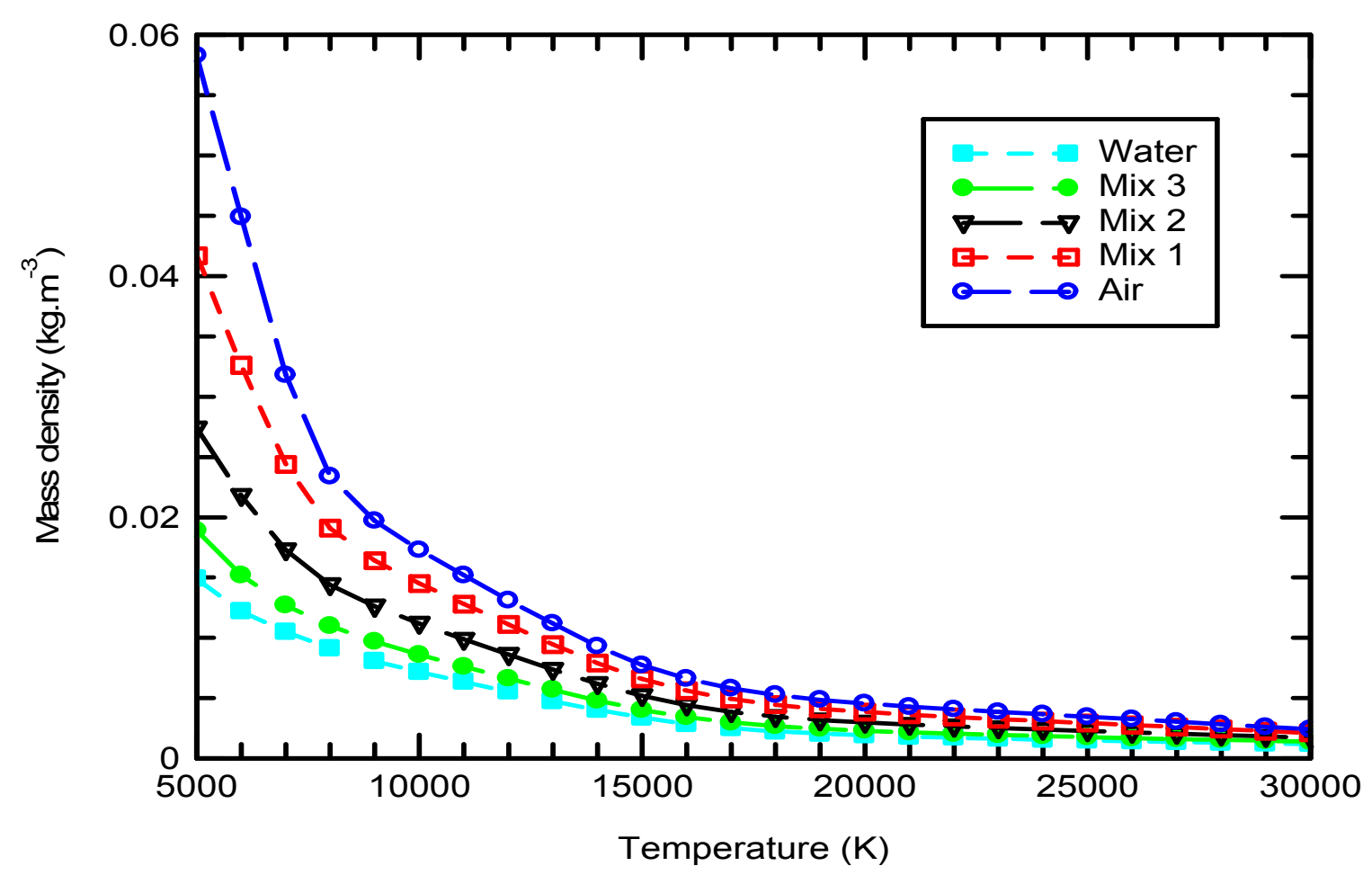

Fig. 2: Mass density evolution of plasma versus temperature at pressure $1 \mathrm{~atm}$.

\subsubsection{ENTHALPY}

The enthalpy $H$ evolution versus temperature of the five chosen plasmas appears on figure 3 . This characteristic increases much with the temperature. The abrupt increases of $H$ take place in the field of temperature corresponding to different chemical reactions: $\mathrm{N}_{2}$ molecules dissociation around $7000 \mathrm{~K}$; ionization of atoms $\mathrm{N}, \mathrm{O}$ and $\mathrm{H}$ around $15000 \mathrm{~K}$; ionization of $\mathrm{N}^{+}$around $27000 \mathrm{~K}$. In addition, for a given temperature, the mixture containing the strongest percentage of hydrogen leads to the highest enthalpy. This is related to the low value of the hydrogen mass density which contributes thus to the increase of the enthalpy $H$.

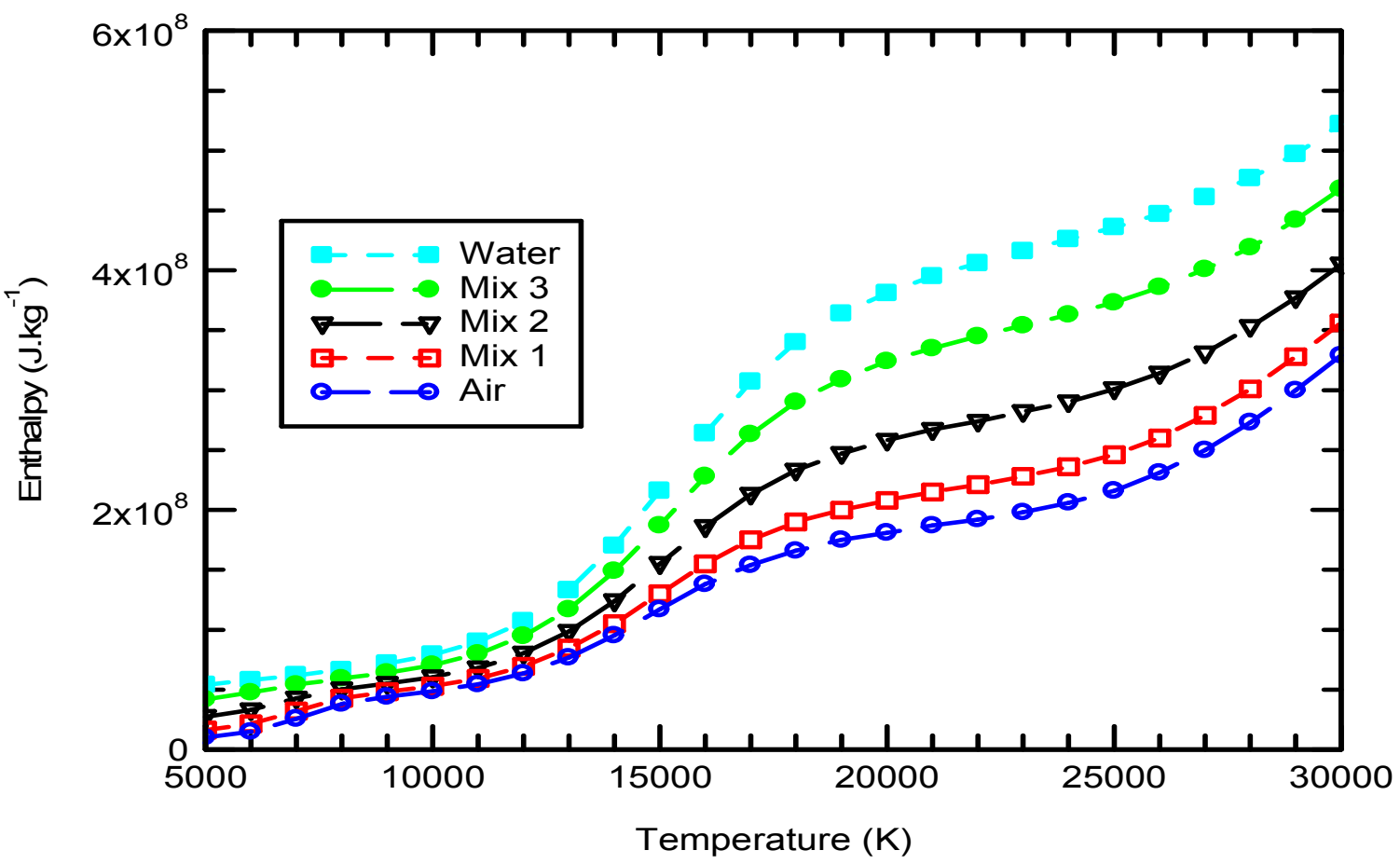

Fig. 3: Enthalpy variation of plasma versus temperature at pressure $1 \mathrm{~atm}$. 


\subsubsection{SPECIFIC HEAT}

The variation, versus temperature, of the different mixtures plasmas specific heat $C_{P}=\frac{\partial H}{\partial T}$ (figure 4) is strongly related to that of the enthalpy. The peaks of $C_{P}$ correspond to reactions of dissociation and ionization. As for the enthalpy, the quantity of hydrogen contained in the mixture determines the value more or less high of the $C_{P}$ maximum.

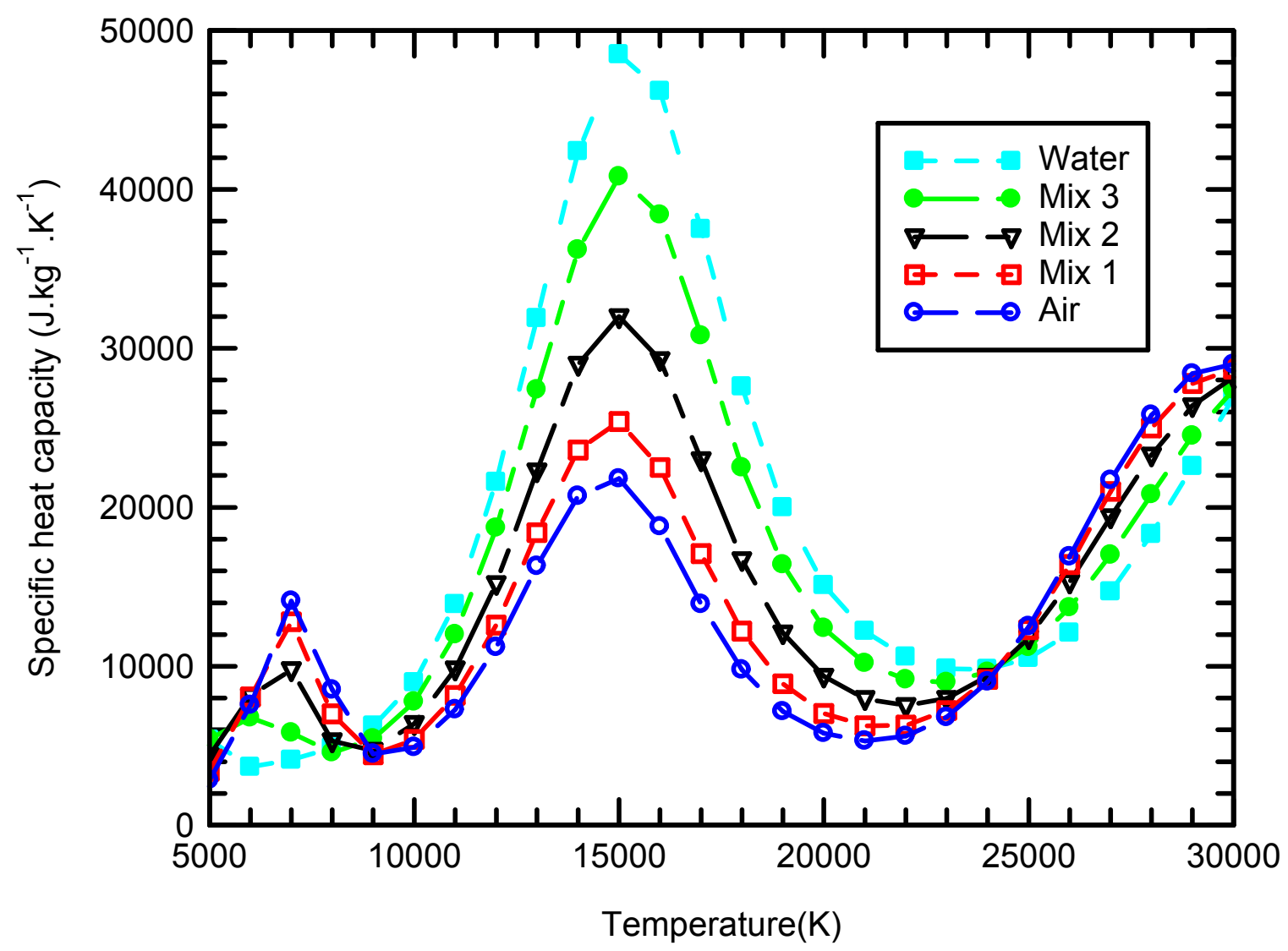

Fig. 4: Specific heat at, constant pressure, of plasma versus temperature at pressure $1 \mathrm{~atm}$.

\subsubsection{SOUND VELOCITY}

Evolution of this characteristic, versus temperature, appears on figure 5 for the five plasmas.
These curves which have a similarity of form reveal that the sound velocity is higher in plasmas resulting from the mixtures with strong proportion of water vapor. 


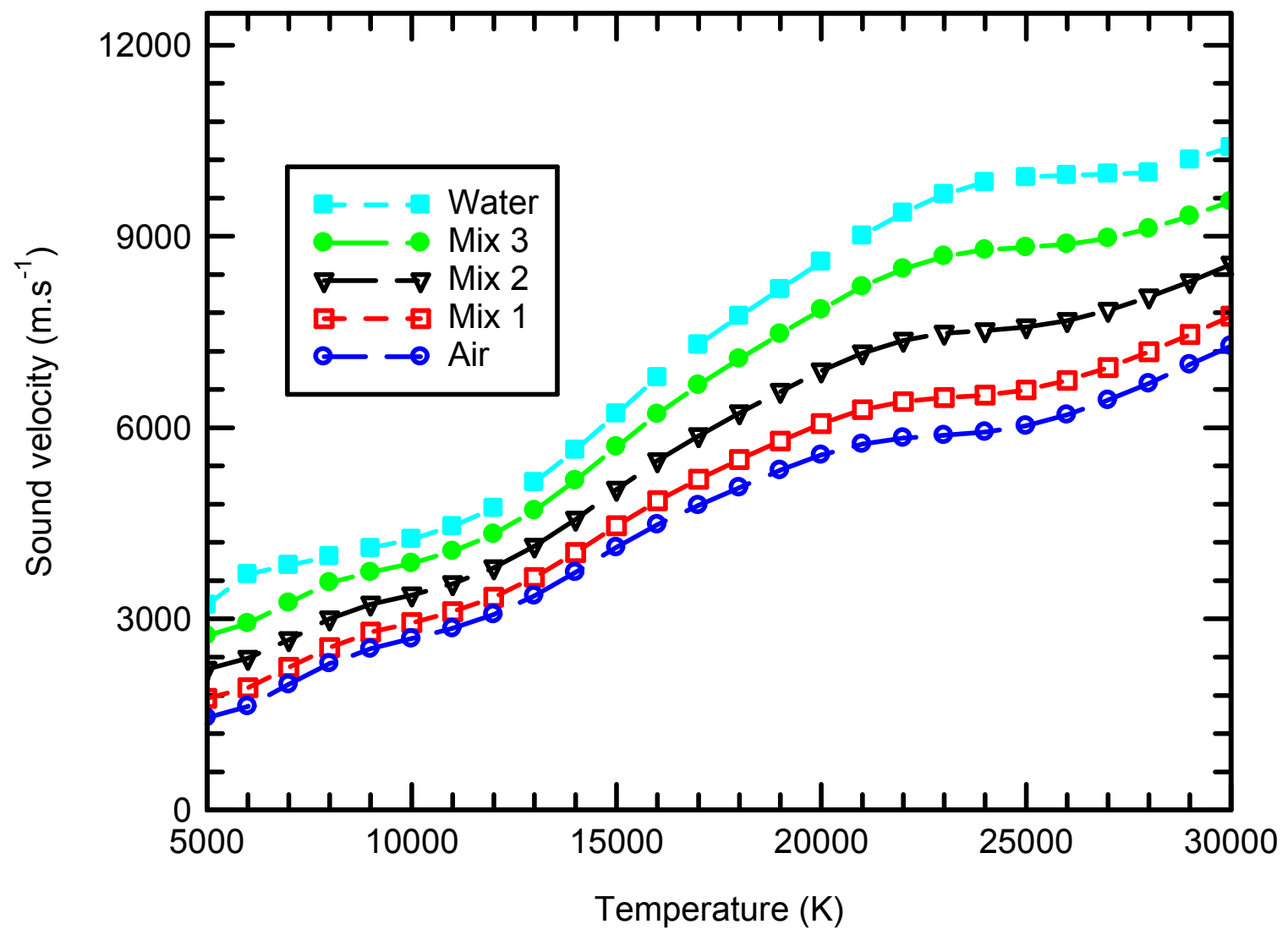

Fig. 5: Sound velocity variation in plasma versus temperature at pressure $1 \mathrm{~atm}$.

Knowing the plasma thermodynamic properties, one can calculate others essential characteristic for the electrical arc modeling in circuit breaker. These characteristics are the enthalpy density (or enthalpy per unit of volume) $\rho H$ and the energy flux (or enthalpy flux) $\rho H a$.

\subsubsection{ENTHALPY DENSITY}

Figure 6 shows the evolution of the enthalpy density, versus temperature, for the studied mixtures. The curves of this figure present a great similarity of form. At first approximation, each mixture plasma enthalpy density can be considered variable little versus temperature. This is due to variations of the mass density and the enthalpy $H$. Indeed, when the temperature increases, $\rho$ decreases whereas $H$ increases. These variations are much slower at high temperature $(T>25000 \mathrm{~K})$. It should especially be noted that for $\mathrm{T}>6000 \mathrm{~K}$, the plasma enthalpy density decreases with the percentage of water vapor in the mixture. 


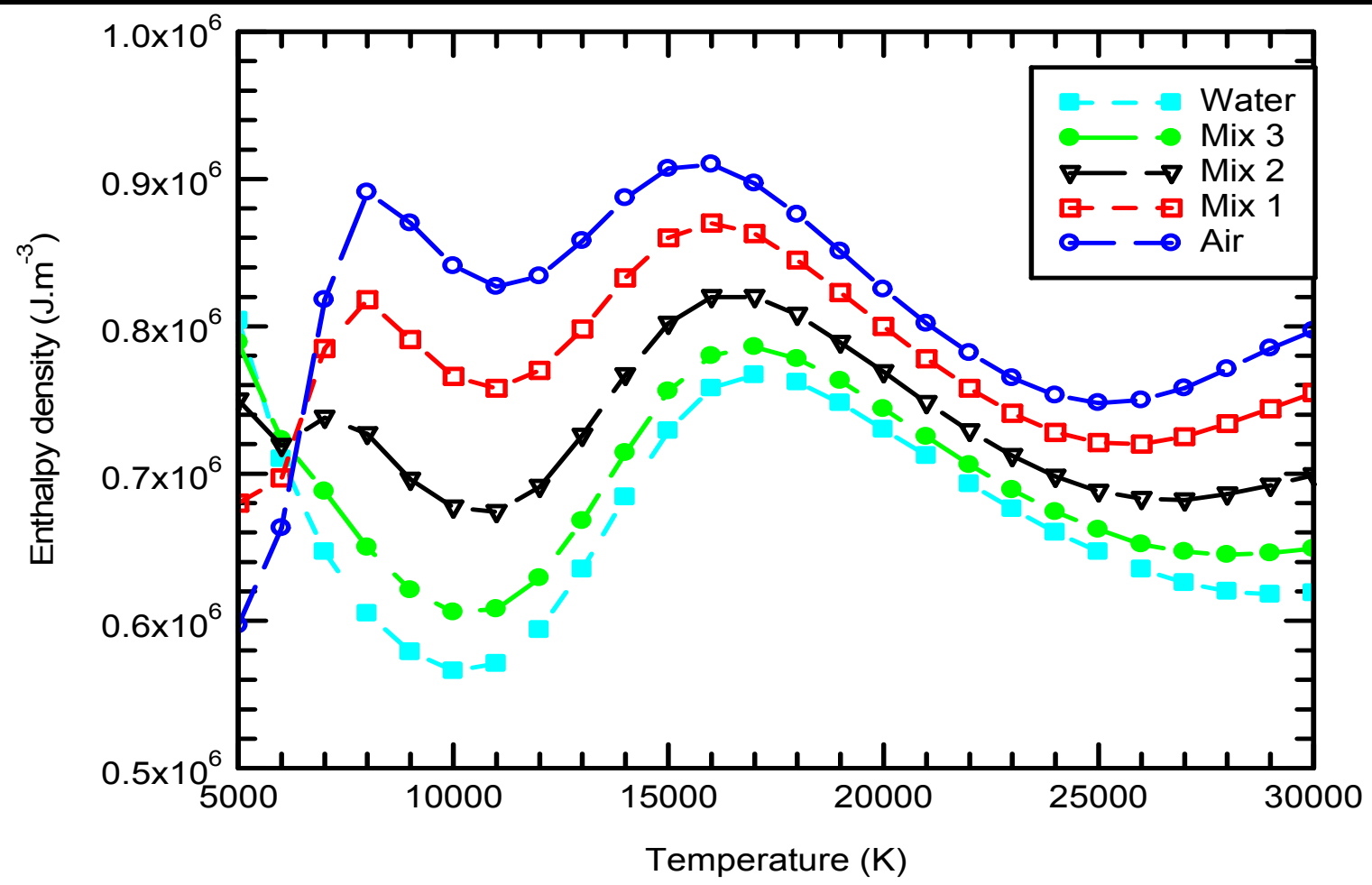

Fig. 6: Enthalpy density variation of plasma versus temperature at pressure $1 \mathrm{~atm}$.

\subsubsection{ENTHALPY FLUX}

This parameter is one of the most significant characteristics when one approach modeling arcs of circuit breakers. The product $\rho H a$ (power flux or enthalpy flux) determine the energy transport capacity of plasma through surfaces of exhaust room of circuit breaker Figure 7 indicates the evolution, versus temperature, of the enthalpy flux relating to plasmas of the five mixtures. The curves show that more the percentage of water vapor in the mixture increases, more the enthalpy flux of the plasma is significant. According to the importance of the value of the enthalpy flux, the classification of the mixtures is as follows: Water, Mix 3, Mix 2, Mix 1 and Air.

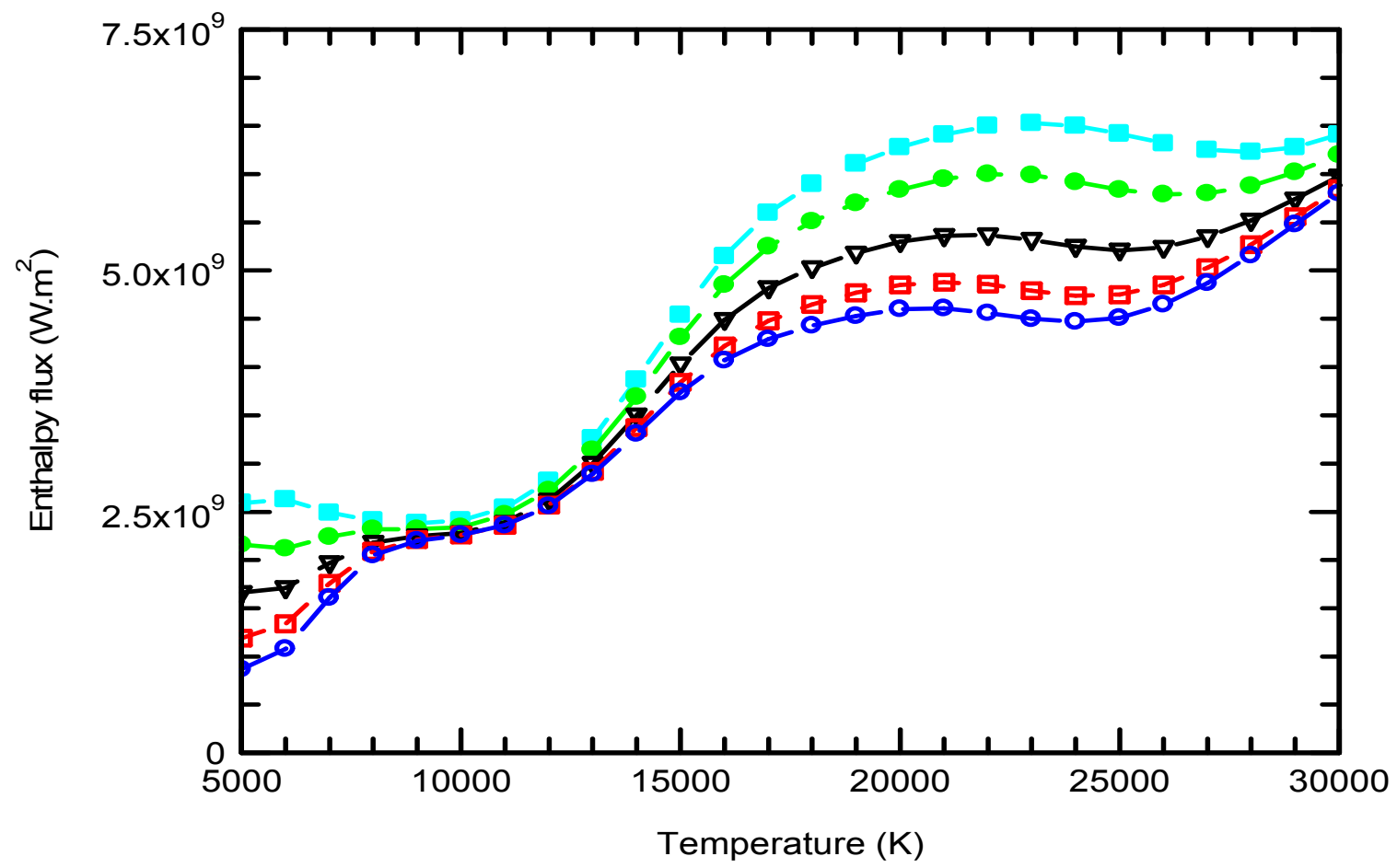

Fig. 7: Enthalpy flux variation of plasma versus temperature at pressure $1 \mathrm{~atm}$. 
3.2. PRESSURE INFLUENCE

This study on selected plasmas shows that concerning the pressure; all these mixtures have the same behavior. We thus limited to the case of plasma resulting to $50 \%$ air $-50 \%$ water vapor mixture (Mix 2), to give the most significant results. The remarks are also valid for plasmas of the other mixtures.

\subsubsection{MASS DENSITY}

The curves of figure 8 represent the variations

of ratio $\frac{\rho}{P}$ of mass density on the pressure of Mix 2 plasma versus temperature, for various values of the pressure. They show that for a given temperature $T$, the mass density increases with the pressure $P$; this is explained by the expression of the state equation. This increase is order of the value of pressure. This phenomenon is due to displacements of the dissociation and ionization equilibrium towards the increasing temperatures. These reactions which contribute to replace the heavy species (mole cules) by species more light (atoms, ions and electrons) appear more tardily when the pressure increases; it results from it, for a given temperature, a rise of $\rho$.

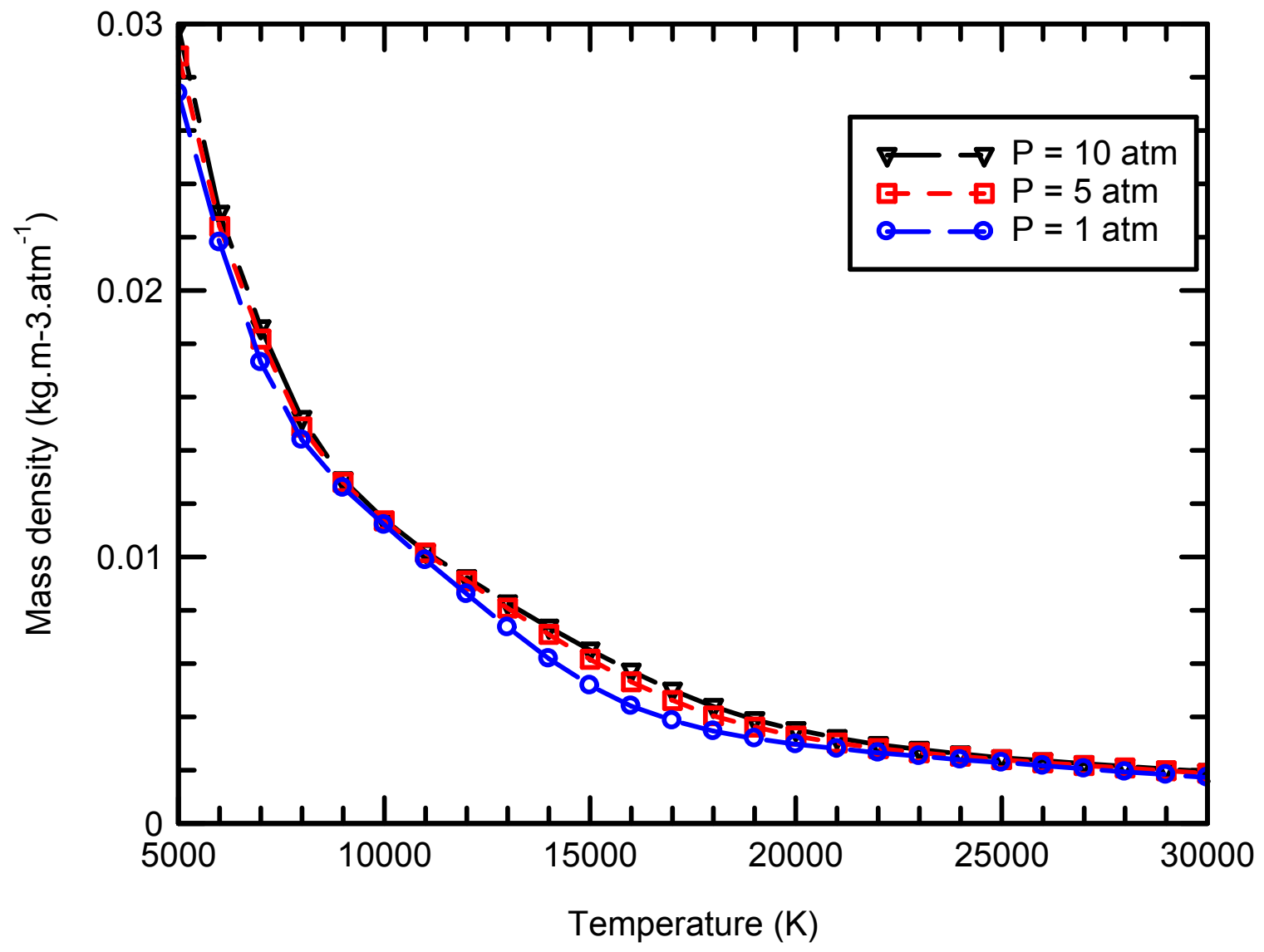

Fig. 8: Ratio $\frac{\rho}{P}$ variation of Mix 2 plasma versus temperature at different pressures.

\subsubsection{ENTHALPY}

For a given temperature (figure 9), the mixtures plasmas enthalpy decreases when the pressure increases. It should be noted that the reduction is more marked in the zones of temperature where dissociations and ionizations of the particles take place. When the pressure increases, the different reactions (dissociation and ionization) occurs, as we already indicated, at higher temperatures. In other words, for a given $\mathrm{T}$, the rise of the pressure involves an increase of the plasma mass density $\rho$. This involves reduction of the enthalpy because it varies in direction reverses of $\rho$. This phenomenon not appears at very low temperature because the neutral molecular species are not very sensitive to the pressure modification. 


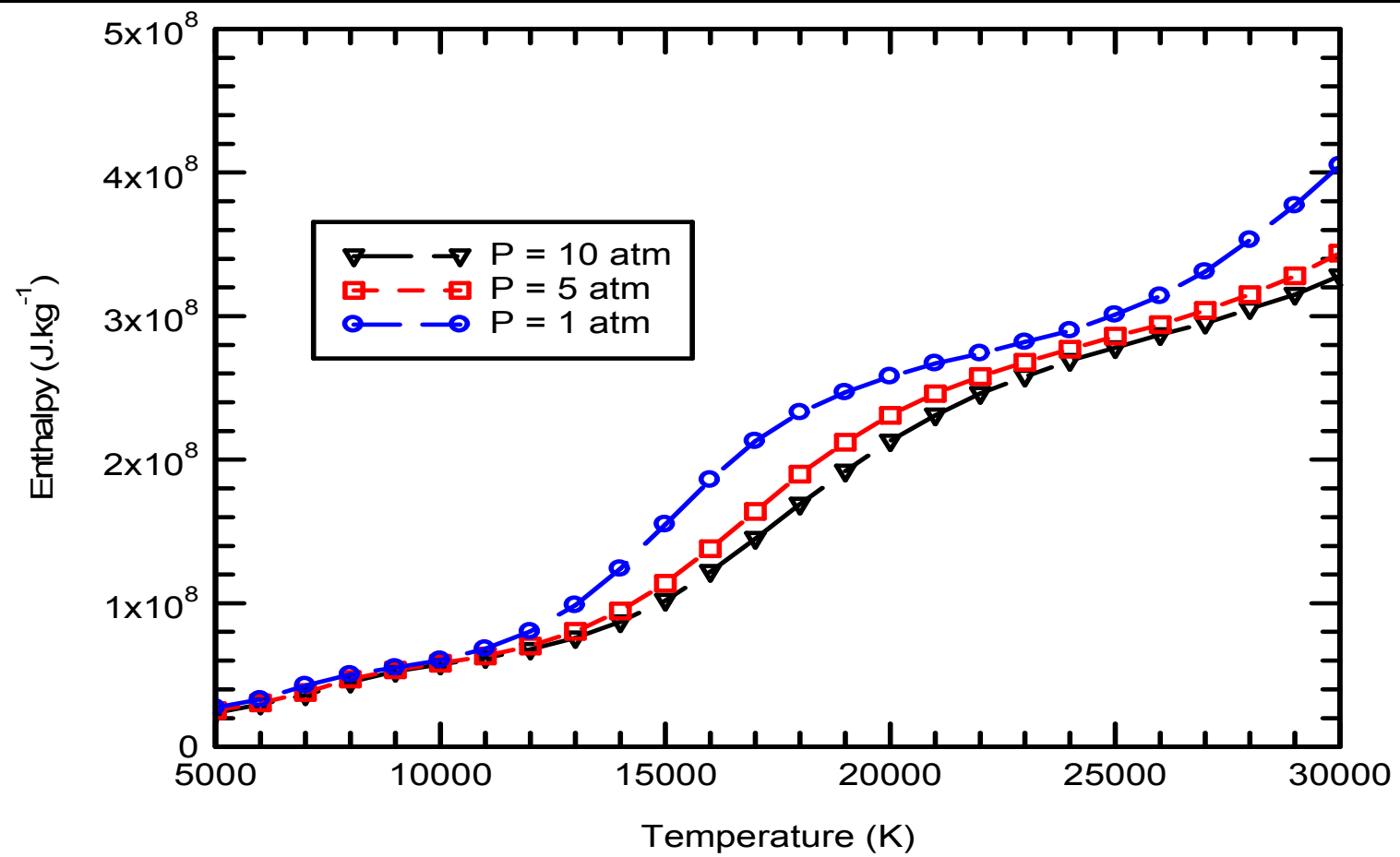

Fig. 9: Evolution of Mix 2 plasma enthalpy versus temperature at different pressures.

\subsubsection{SPECIFIC HEAT}

The pressure influence on the specific heat $\left(C_{P}\right.$ ) of plasma of $50 \%$ air $-50 \%$ water vapor mixture (Mix 2 ) is shown on figure 10. Increase of the pressure involves a maximum translation (towards the higher temperatures) and a light lowering of their values. This phenomenon is related to the enthalpy evolution versus pressure. Indeed, in the range of temperature studied, the increase of the pressure leads to a relatively slow evolution of the numerical densities of the particles. It results from it a slower variation of enthalpy and consequently, a weak reduction of the specific heat at constant pressure peaks value.

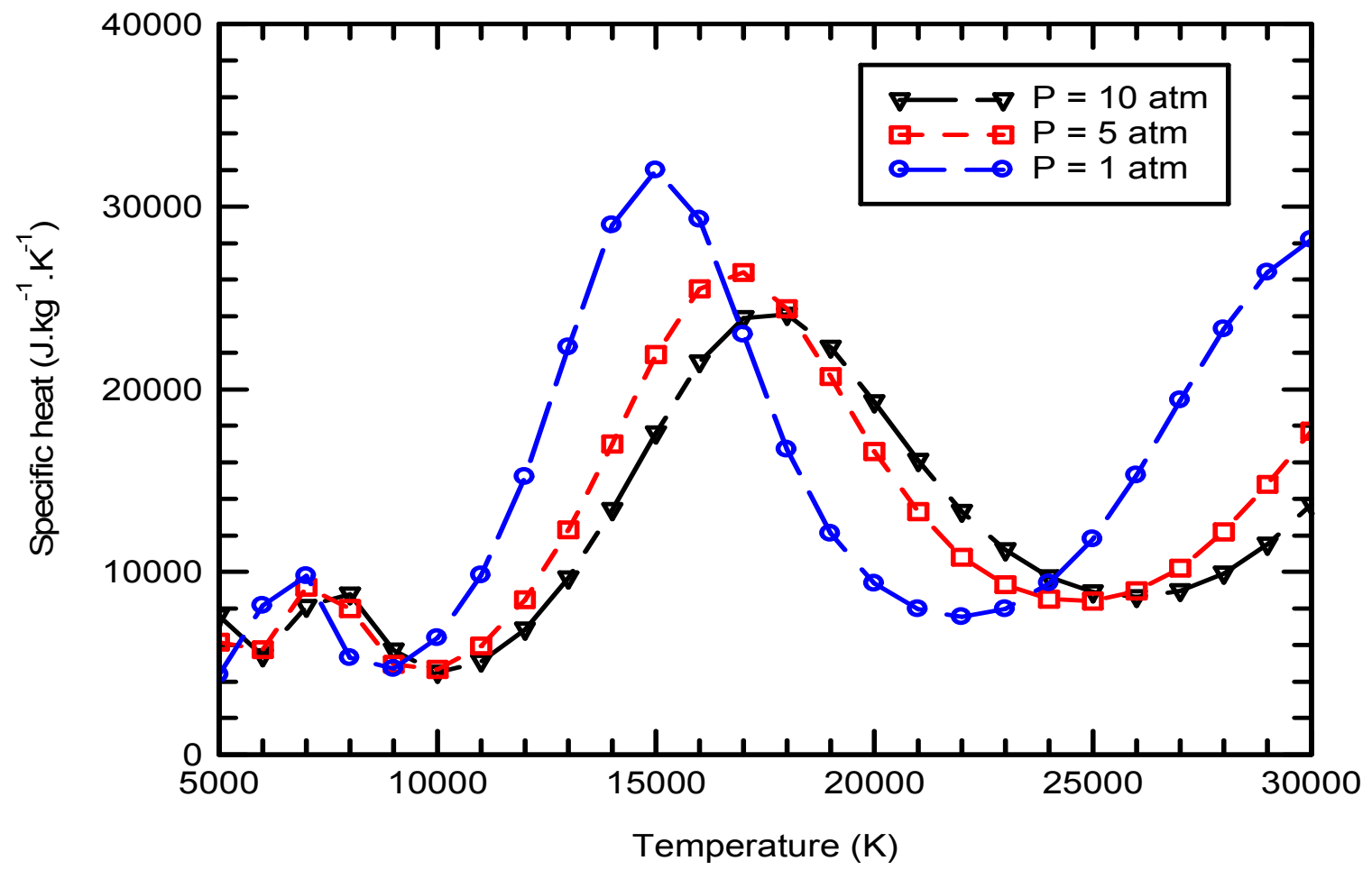

Fig. 10: Specific heat variation of Mix 2 plasma versus temperature at different pressures. 
3.2.4. SOUND VELOCITY

The pressure influence on the sound velocity

(a) of $50 \%$ air $-50 \%$ water vapor mixture plasma (Mix

2 ) is presented on figure 11 . The sound velocity in Mix 2 plasma varies very little with the pressure. For a given temperature, it decreases slightly when the pressure increases. The maximum variations which take place in the zone of ionization (12000 - $24000 \mathrm{~K}$ ) don't exceed $12 \%$ when the pressure varies from 1 to $10 \mathrm{~atm}$.

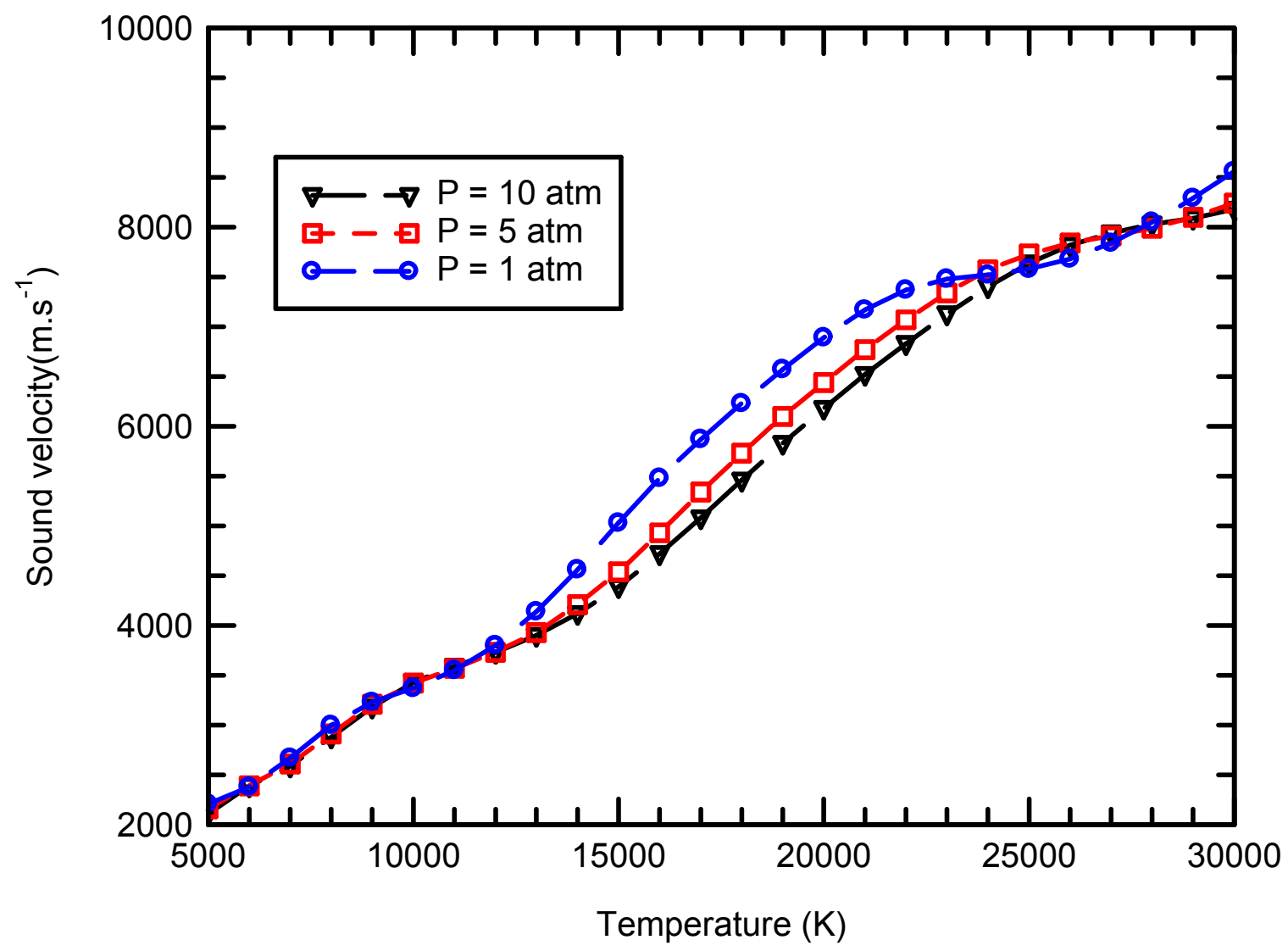

Fig. 11: Sound velocity variation of Mix 2 plasma versus temperature at different pressures

\subsubsection{ENTHALPY DENSITY}

The evolution, versus temperature, of the ratio $\frac{\rho H}{P}$ of the enthalpy density on the pressure of Mix 2 plasma is represented on figure 12. For the same temperature one observes not very significant variations except the zones of reaction (dissociation and ionization) temperatures. When the pressure varies from 1 to $10 \mathrm{~atm}$, the maximum variation of $\frac{\rho H}{P}$ is $13 \%$ at $15000 \mathrm{~K}$. While neglecting the undulations observed, probably due to the various chemical reactions, one can by approximation consider that the plasma enthalpy density is directly proportional to the pressure. 


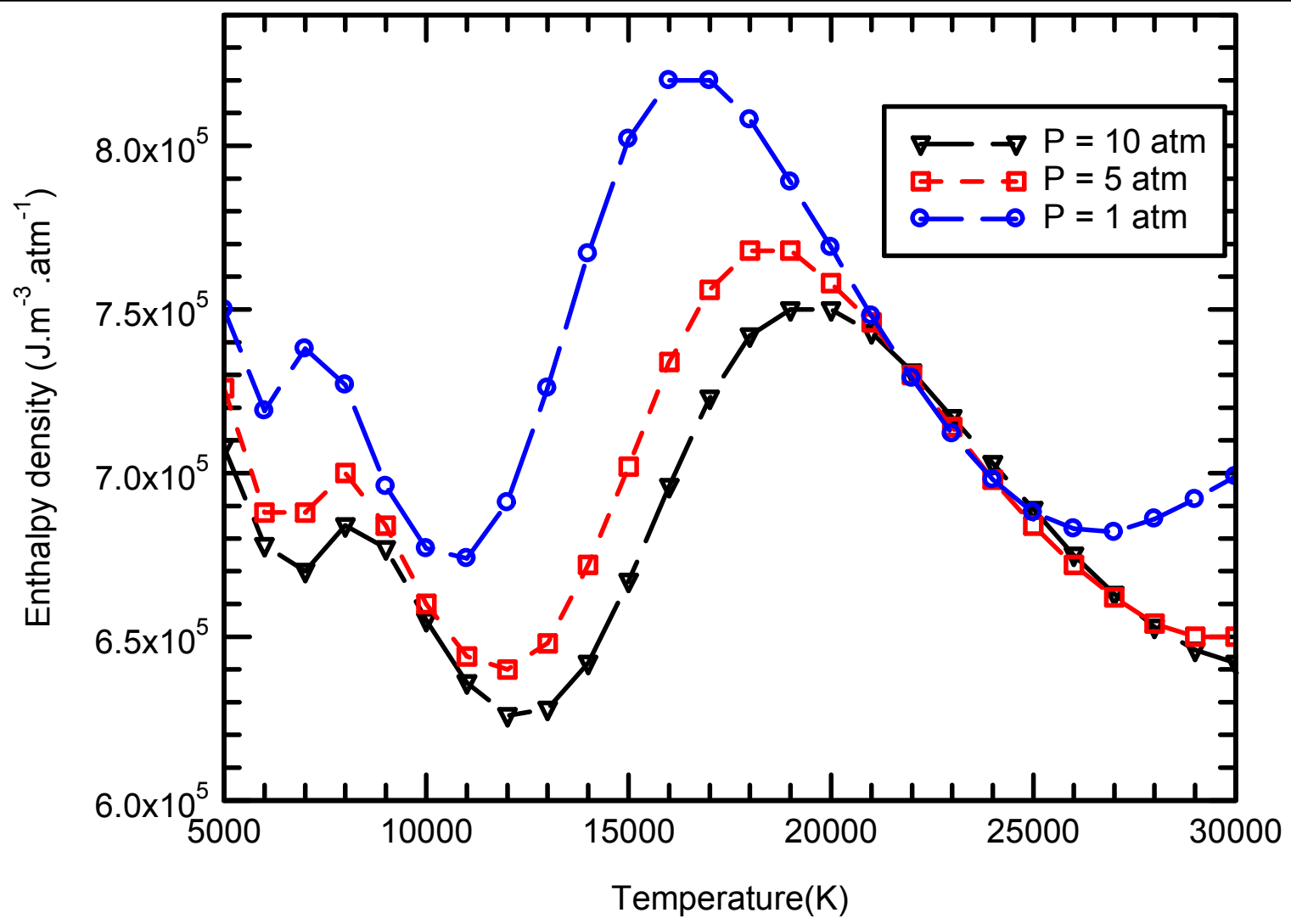

Fig. 12: Evolution of the ratio $\frac{\rho H}{P}$ for Mix 2 plasma versus temperature at different pressures.

\subsubsection{ENTHALPY FLUX}

Figure 13 represent the evolution versus temperature of the ratio $\left(\frac{\rho H a}{P}\right)$ of Mix 2 plasma at different values of pressure. This figure highlights the pression $(P)$ influence on the plasma enthalpy flux. The remarks relating to the pression influence on the plasma enthalpy density are also valid for the plasma enthalpy density. Under these conditions $\left(\frac{\rho H a}{P}\right)$ is also approximatively proportional to the pressure because plasma sound velocity vary very little with this one (section 3.2.5). 


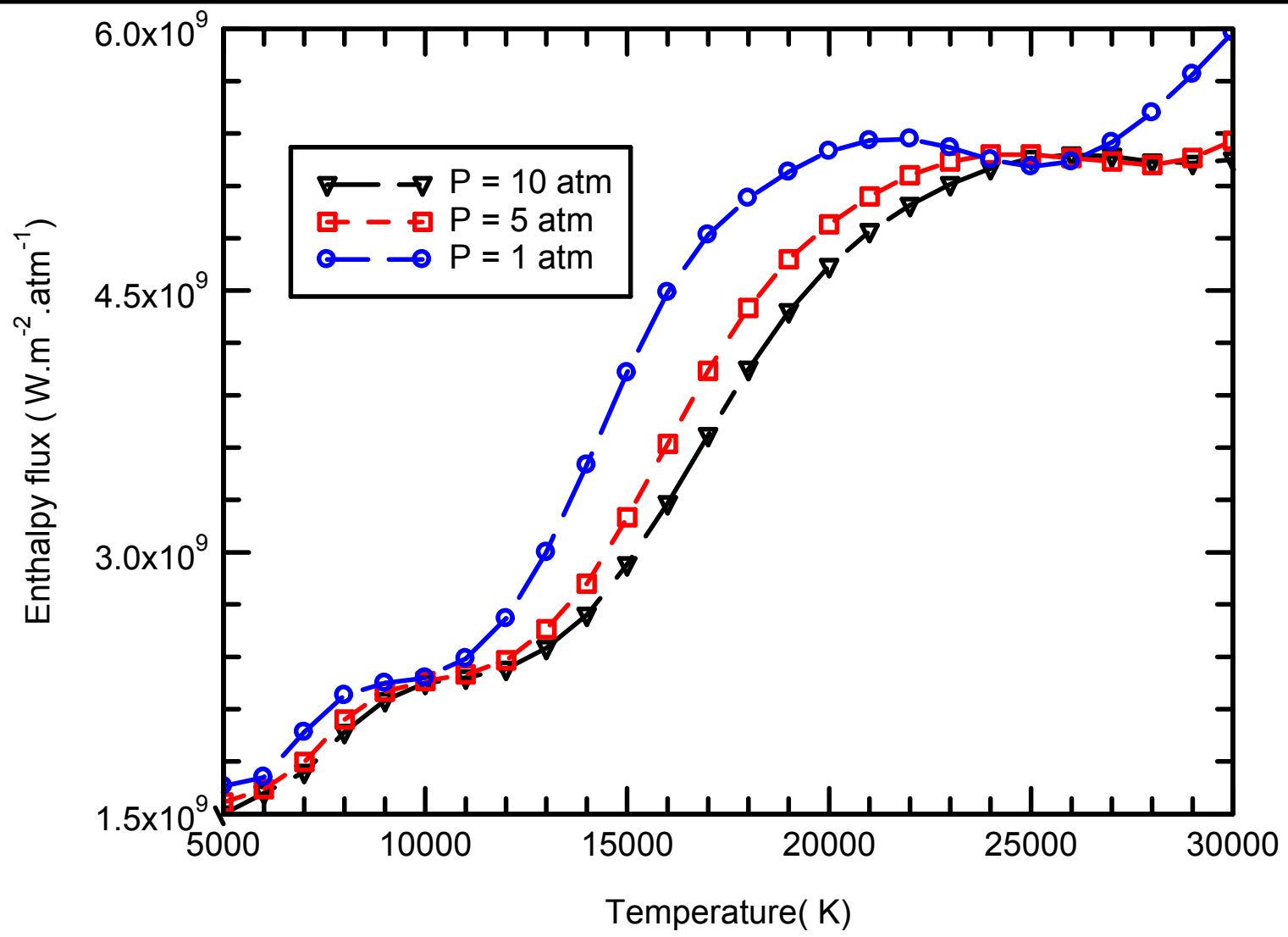

Fig. 13: Evolution of the ratio $\frac{\rho H a}{P}$ for Mix 2 plasma versus temperature at different pressures.

\section{CONCLUSION}

Thermodynamic properties serve as indispensable input for theoretical modeling and important ingredients for experimental understanding. In this paper, the calculation of three air and water vapor mixtures thermal plasmas thermodynamic properties is carried out. Calculation is made in the range of temperature going from $5000 \mathrm{~K}$ to $30000 \mathrm{~K}$ and for three values of pressure based on the assumption of local thermodynamic equilibrium.

All the equations necessary to determine accurately the thermodynamic properties of studied plasmas have been given.

Results show that the water vapor improves the thermodynamic properties of the mixture plasma on most of the temperature range $(9000 \mathrm{~K}$ to $25000 \mathrm{~K})$. What could have a positive influence on the cut of the current in this mixture.

But, it is clear that these results are not sufficient to be able to come to a conclusion about this subject. Although some other parameters (electrodes oxidation, dielectrical rigidity, etc.) will have to be taken into account; these results can already be used in the modeling of the discharges of electrical arcs in the airwater vapor mixture. The influence of the pressure is also studied. It results that the pressure increase involves a translation of the characteristics of plasma towards high temperatures.

\section{ACKNOWLEDGEMENTS}

The authors would like to present their cordial thanks to all persons who contributed in this work and the journal reviewers for their careful reading.

\section{REFERENCES}

Abbaoui, M., Koalaga, Z. and Lefort, A., 1992. Propriétés thermodynamiques et de transport des Plasmas issus de la vaporisation des isolants PTFE et PE. J. Phys. III France 2 : 455472.

Abbaoui, M., Koalaga, Z. and Lefort, A., 1993. Composition et coefficients de transports des plasmas de matériaux plastiques (polymères). Can. J. Phys 71: 1291.

Andanson, P., Lefort, A. and Roche, J., 1979. Erosion des contacts électriques sous l'effet d'un arc électrique de forte intensité. J. Phys D: Appl. Phys 12.

Andanson, P. and Leffort, A., 1984. Calcul de l'érosion par vaporisation au niveau de la tache cathodique. J. Phys.D : Appl. Phys 17: 23772386.

André, P., Brunet, L., Bussière, W., Caillard, J., Lombard, J. M. and Picard, J. P., 2004. Transport 
vapours: Application to PE, POM, PMMA PA66 and PC. Eur. Phys. J. Appl. Phys 25: 169-182.

André, P., 1996. Composition and thermodynamic properties of ablated vapour of PMMA, PA6-6, PETP, POM and PE. J. Phys. D: Appl. Phys 29: 1963-1972.

André, P., 1997. The influence of graphite on the composition and thermodynamic properties of plasma formed in ablated vapour of PMMA, PA6-6, PETP, POM and PE used in circuitbreakers. J. Phys. D: Appl. Phys 30: 475-493.

André, P., 1997. Etude d'un plasma de SF6 hors d'équilibre thermique. J. Phys. III Fance 7 : 1339- 1359.

André, P., Brunet, L., Duffour, E. and Lombard, J. M., 2002. Composition, pressure and thermodynamic properties calculated in plasma formed in insulator vapours of $P C$ and $P O M$ at fixed volume. Eur. Phys. J. AP 17: 53-64.

André, P., 1995. Etude de la composition et des propriétés thermodynamiques des plasmas thermiques à l'équilibre et hors d'équilibre thermodynamique. Thèse, Univ. Clermont Ferrand, France.

Aubreton, J., Elchinger, M. F., Fauchais, P., Rat, V. and André, P., 2004. Thermodynamic and transport properties of a ternary $\mathrm{Ar}-\mathrm{H}_{2}-\mathrm{He}$ mixture out of equilibrium up to $30000 \mathrm{~K}$ at atmospheric pressure. J. Phys. D: Appl. Phys 37: 22322246.

Aubreton, J., Elchinger, M. F. and Vinson, J. M., 2008. Transport coefficients in water plasma: Part I: Equilibrium Plasma. Plasma Chem Plasma Process 29: 149-171.

Bussière, W. and André, P., 2001. Evaluation of the composition, the pressure, the thermodynamic properties and the monatomic spectral lines at fixed volume for a SiO2-Ag plasma in the temperature range 5000-25 $000 \mathrm{~K}$. J. Phys. D: Appl. Phys 34:1657-1664.

Cheminat, B. and Andanson, P., 1986. Etude expérimentale d'une décharge d'arc électrique contaminée par des vapeurs d'isolants. Revue Phys. Appl 2 : 187-193.

Cheminat, B., 1989. Influence de l'ablation des parois sur les caractéristiques d'un arc électrique laminé. Revue Phys. Appl 24 : 277-284.

Ghorui, S., Heberlein, J. V; R. and Pfender, E., 2008. Thermodynamic and Transport Properties of Two-Temperature Nitrogen-Oxygen Plasma. Plasma Chem Plasma Process 28:553-582.

Hannachi, R., 2007. Etude expérimentale et propriétés radiatives d'un plasma thermique induit par impact LASER à la surface de milieux H2O -
$\mathrm{CaCl} 2 / \mathrm{MgCl} 2 / \mathrm{NaCl}$. Thèse, Univ. Toulouse, France.

Hrabovsky, M., Kopecky, V., Sember, V., Kavka, T., Chumak, O. and Konra'd, M., 2006. IEEE Trans Plasma Sci 34: 1566.

Hrabovsky, M. and Krenek, P., 1993. Proceedings of the 11 th international symposium on plasma Chemistry. Loughborough p 315.

Kagoné, A. K., Koalaga, Z. et Zougmoré, F., 2012. Calcul de composition de plasmas thermiques d'arc électrique de mélanges d'air et de vapeur d'eau. Rev. can. Phys $90: 211-221$.

Kagoné, A. K., Koalaga, Z. et Zougmoré, F., 2012. Calculation of air-water vapor mixtures thermal plasmas transport coefficients. IOP Conf. Series: Materials Science and Engineering 29: 012004.

Kagoné, A. K., 2012. Caractérisation théorique de plasmas thermiques d'arc électrique de mélanges d'air et de vapeur d'eau : Application au disjoncteur basse et moyenne tension. Thèse, Univ. Ouagadougou, Burkina Faso.

Koalaga, Z., 1991. Contribution à l'étude expérimentale et théorique des plasmas d'arcs électriques laminés. Thèse, Univ. Clermont Ferrand, France.

Koalaga, Z., Abbaoui, M. et Lefort, A., 1993. Calcul des propriétés thermodynamiques des plasmas d'isolants $\mathrm{C}_{\alpha} \mathrm{H}_{\beta} \mathrm{O}_{\gamma} N_{\theta}$. J. Phys. D. Appl. Phys $26: 393-403$.

Kohio, N., Kagoné, A. K., Koalaga, Z., Zougmoré, F. and Njomo, D., 2014. Calculation of transport coefficients of air - water vapor mixtures thermal plasmas used in circuit breakers. International Journal of Engineering Research 3: 711 - 715.

Kohio, N., Kagoné, A. K; Koalaga, Z. and Zougmoré, F., 2014. Composition of Air - Water Vapor Mixtures at Low Temperatures, International Journal of Advanced Research in Science, Engineering and Technology. $1: 240-246$.

Maouhoub, E., 1997. Contribution à l'étude de l'influence de la molécule de $\mathrm{CO}_{2}$ sur un plasma de mélange $\mathrm{Ar}-\mathrm{CO}_{2}$. Thèse, Univ. Clermont Ferrand, France.

Ouajji, H., Cheminat, B. and Andanson, P., 1986. Composition et conductivité d'un plasma aircuivre. J. Phys. D : Appl. Phys 19 : 1903-1916.

Petr, K., 2008. Thermophysical properties of H2O-Ar plasmas at temperatures $400-50000 \mathrm{~K}$ and pressure 0,1MPa. Plasma Chem Plasma Process 28: 107-122. 
